\title{
Spatial distribution of atmospheric carbon monoxide over Bay of Bengal and Arabian Sea: Measurements during pre-monsoon period of 2006
}

\author{
V R Aneesh, G Mohankumar* and S Sampath \\ Atmospheric Sciences Division, Centre for Earth Science Studies, PB No. 7250, Akkulam, \\ Thiruvananthapuram 695 031, India. \\ *e-mail: gmk4833@yahoo.com
}

\begin{abstract}
Indian Space Research Organization (ISRO) conducted the 'Integrated Campaign for Aerosols, gases and Radiation Budget (ICARB)' for a two-month pre-monsoon period in 2006 with the ocean segment covering Bay of Bengal and Arabian Sea. During this campaign, carbon monoxide (CO) was continuously monitored using a non-dispersive IR analyser. Quantifying CO in ambient air is vital in determining the air quality of a region. Being toxic, $\mathrm{CO}$ is a criteria pollutant, but it is a weak green house gas. Globally, very few measurements exist over marine atmospheres to study its temporal pattern; particularly in situ $\mathrm{CO}$ measurements are few over the Bay of Bengal and Arabian Sea for comparison. Present measurements indicate: (i) predominant single peak in the diurnal pattern of $\mathrm{CO}$ over the marine atmosphere in contrast to the double peak over the continent, (ii) the mean diurnal $\mathrm{CO}$ over the marine atmosphere showing an increasing trend towards evening hours, (iii) the amplitude of the AN peaks over the marine atmosphere was $\sim 100 \mathrm{ppbv}$, while at a remote island site in the Indian Ocean it was $\sim 5 \mathrm{ppbv}$ and (iv) high $\mathrm{CO}$ values were observed close to continent and the long range transport by wind also caused $\mathrm{CO}$ highs.
\end{abstract}

\section{Introduction}

The air quality index of a region specifies the levels of tolerance of trace gases in the Earth's atmosphere. With growing industrialisation and advancement in technology, the amount of emission of trace gases, mainly of anthropogenic origin that finds its way to the atmosphere, is on the increase. $\mathrm{CO}$ is not a strong green house gas, but is toxic and has a sink in the biosphere through the respiratory cycle of higher order animals. CO, a product of all forms of incomplete combustion, is present at concentrations of $50-500 \mathrm{ppbv}$ in the troposphere. Its principal sink is $\mathrm{OH}$, the main tropospheric oxidant. CO has a mean atmospheric lifetime of two months against oxidation by $\mathrm{OH}$ and is also a sensitive tracer for continental outflow and intercontinental transport of pollution (Khalil and Rasmussen 1994; Khalil 1995; Yurganov 2000; Climate Change 2001; Jockel et al 2002). Though weak, oceans are a known natural source of atmospheric CO (Swinnerton et al 1970). Only a few measurements of $\mathrm{CO}$ exist over tropical marine atmosphere. Springer-Young et al (1996) have estimated the CO gradient in the marine boundary layer of the north Atlantic, besides the tropospheric $\mathrm{CO}$ modelling with the possible influence of the ocean (Erickson et al 1992).

The 'Integrated Campaign for Aerosols, gases and Radiation Budget (ICARB)' was organized under the Geosphere Biosphere Programme of ISRO (ISRO-GBP) with Space Physics Laboratory (SPL), Thiruvananthapuram as the nodal institution, during the pre-monsoon period of 2006 (from mid-March to mid-May) (Moorthy et al 2006). The campaign, which was the first of its kind, included

Keywords. Carbon monoxide; pre-monsoon; marine atmosphere; Bay of Bengal; Arabian Sea. 
three segments viz., land, ocean and air. In the ocean segment, all aerosol parameters and a few trace gases $\left(\mathrm{CO}, \mathrm{O}_{3}, \mathrm{NO}_{x}\right.$, etc.) were measured onboard the research vessel ORV Sagar Kanya of the Department of Ocean Development, Government of India. Centre for Earth Science Studies (CESS) participated both in the ocean and land segments of ICARB by measuring onboard CO in the marine atmosphere and surface ozone in the ambient air on land over Thiruvananthapuram. The objective of the measurements was to characterize the temporal and spatial nature of $\mathrm{CO}$ over maritime atmosphere and to examine the factors affecting $\mathrm{CO}$ in the marine atmosphere. Surface ozone was being monitored over land at Thiruvananthapuram and the data examined during the campaign period did not vary at the site when compared to a similar season in a yester year. Only the maritime CO measurements are discussed in this paper.

\section{Method of measurement}

Carbon monoxide concentration in the ambient air over the ocean surface was measured continuously using an IR analyser, Monitor Europe Model $9830 \mathrm{~B}$ that measures the ambient CO in four ranges. The $\mathrm{CO}$ analyzer measures the concentration of the gas in the ambient air by nondispersive infrared spectroscopic absorption at the Infra Red (IR) wavelength of $4.6 \mu \mathrm{m}$. A gas filter correlation wheel rejects the interferers in the air sample and the narrow band-pass filter measures the CO sensitive IR wavelengths. The instrument has a built-in catalytic zero air scrubber that provides $\mathrm{CO}$-free air to the analyzer as reference for setting the zero reading after the analyzer has sampled air through the converter. The analyzer is very sensitive and is capable of measuring CO from 0-200 ppmv in four ranges and has an auto-ranging facility. The lowest CO level detectable is close to $10 \mathrm{ppbv}$ (full range) and the accuracy of measurement is $1 \%$ of measured value in the lowest range. Data were recorded regularly at 5 minute intervals, round the clock. More details are available elsewhere (Mohankumar et al 2004). This instrument is internally calibrated against a known source of $\mathrm{CO}$ gas that is traceable to National Institute of Standards and Technology, USA. This calibration was checked routinely and was found to be valid till the analyzer characteristics (such as CO timed span, span comparison or CO span ratio) do not change from the initial calibration.

The instrument was operated onboard the ship ORV Sagar Kanya from 15 March to 13 April 2006,

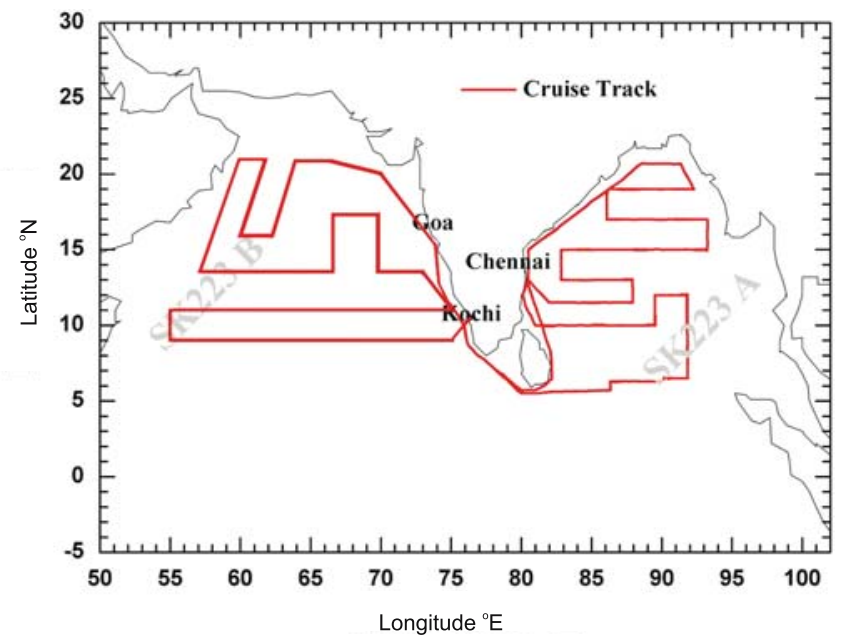

Figure 1. Cruise track.

measuring $\mathrm{CO}$ over the Bay of Bengal and from 18 April till the close of the ICARB on 10 May 2006, measuring $\mathrm{CO}$ over the Arabian Sea. Throughout the campaign, the analyser was operated in the $0-50 \mathrm{ppm}$ range. One GPS receiver onboard the ORV provided coordinates of the vessel. Two automatic weather stations (AWS) installed on the port and starboard sides of the vessel provided the weather data, besides the hourly manual meteorological measurements (wind speed, wind direction, pressure, dry and wet bulb temperature and the sea surface temperature). The average speed of the ship was about 10 knots (nautical miles/hour).

The air inlet to the analyser, which is a $3 \mathrm{~m}$ long duct, was provided through a common air inlet sheltered from rain and the ship's smoke stack. The common air inlet was orthogonal to the direction of the motion of the ship and ahead of the smoke stack, far away in height and close to the deck in order to ensure minimal interference with the stack plume. The CO analyser was installed in an airconditioned room and on a stable platform where the effects of pitching and rolling of the ship were minimum. The analyser was set to operate round the clock and the data access interval selected was 5 minutes.

Spatial and temporal variation of $\mathrm{CO}$ over the ocean could be established by the measurements along the zigzag cruise track (figure 1). CO data for the entire cruise period was available for analysis except during a power failure, which was only once, for a couple of hours. While processing the data, very high values observed during the start up sequence of the analyser were not included in the analyses. The stabilization time required for the analyser after switching on is about 3 hours. 


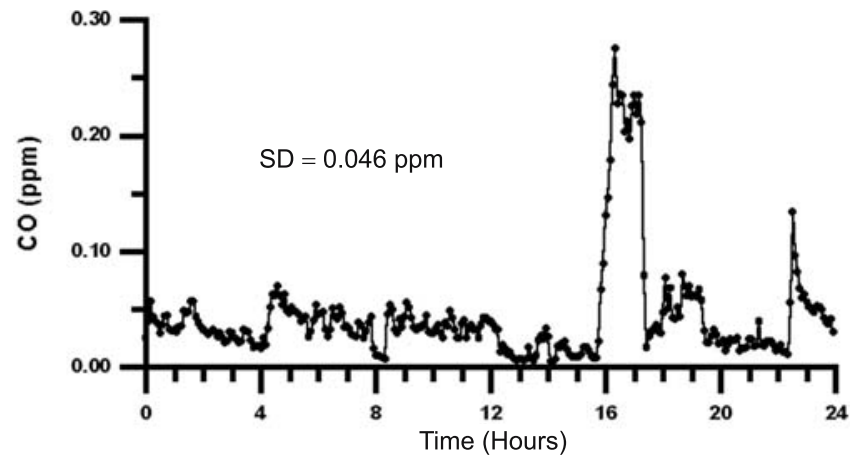

Figure 2. Typical diurnal variation of $\mathrm{CO}$ over Bay of Bengal on 28.03.06.

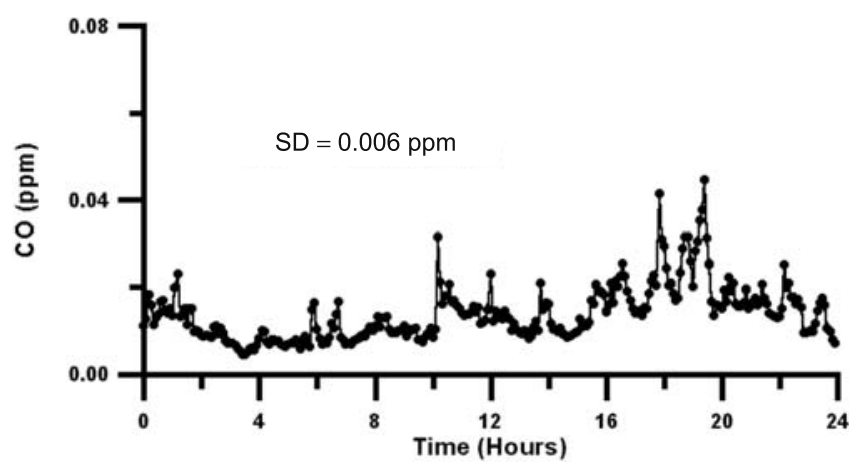

Figure 3. Typical diurnal variation of CO over Arabian Sea for the day 22.04.06.

\section{Results and discussion}

\subsection{Diurnal CO over oceans}

The data were initially analysed to examine the diurnal pattern in $\mathrm{CO}$, if any, like that over the land, discussed in the succeeding section. No typical diurnal variation with recurring peaks at fixed hours of the day was observed both over the Bay of Bengal and Arabian Sea. This could be due to the fact that the position of the measurement site was spatially and temporally varying. Also the background of ocean surface and its source are more or less consistent and highly invariant with nil to negligible anthropogenic source contribution. However, in the afternoon (AN) hours, single peaks were observed over both the seas. Typical diurnal variation in $\mathrm{CO}$ observed over Bay of Bengal for the day 28 March 2006 (standard deviation, $\mathrm{SD}=0.046 \mathrm{ppm}$, with values ranging from 0.01 to $0.28 \mathrm{ppm}$ ) is shown in figure 2 and over the Arabian Sea for the day 22 April $2006(\mathrm{SD}=0.006 \mathrm{ppm}$, values in the range 0.005 to $0.045 \mathrm{ppm}$ ) is depicted in figure 3. The higher standard deviation over Bay of Bengal compared to Arabian Sea is attributed to the larger variation in CO levels over the Bay.

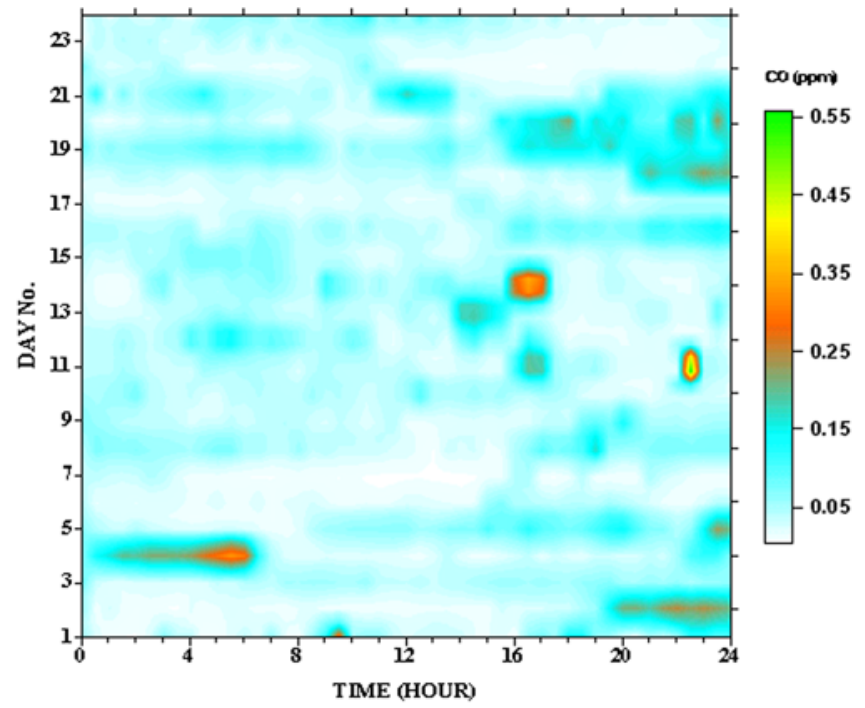

Figure 4. $\mathrm{CO}$ variation over Bay of Bengal.

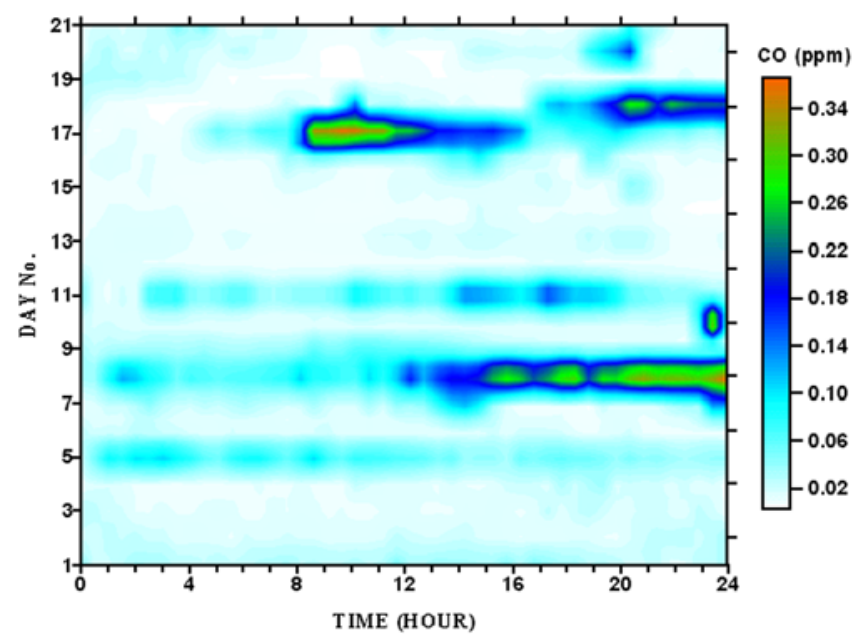

Figure 5. CO variation over Arabian Sea.

The AN increase in CO over both Bay of Bengal and Arabian Sea suggests that similar atmospheric dynamics existed over the two water bodies. The AN peaks in CO during ICARB show larger variations than those observed by Gros et al (2005) in a remote island in the Indian Ocean. Diurnal variation of $\mathrm{CO}$ over remote marine atmosphere in the tropical Indian Ocean as observed by Gross et al (2005) during 1996-2000 and since 2004 confirms a regular low afternoon increase of $1-5 \mathrm{ppbv}$. Variation in the CO levels did occur, but was not periodic. From the time versus day image of $\mathrm{CO}$ (figures 4 and 5) it is evident that most of the enhancements in the $\mathrm{CO}$ levels occurred during the afternoon hours both over the Bay of Bengal and Arabian Sea. The ship does not offer a stationary platform from which regular recurrence of such diurnal peaks could easily be discerned. Due 


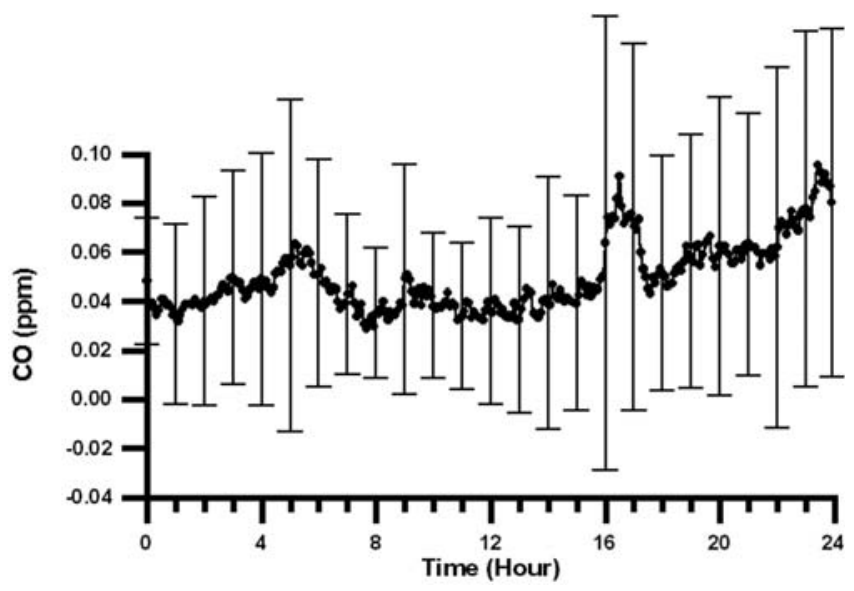

Figure 6. Mean diurnal variation over Bay of Bengal.

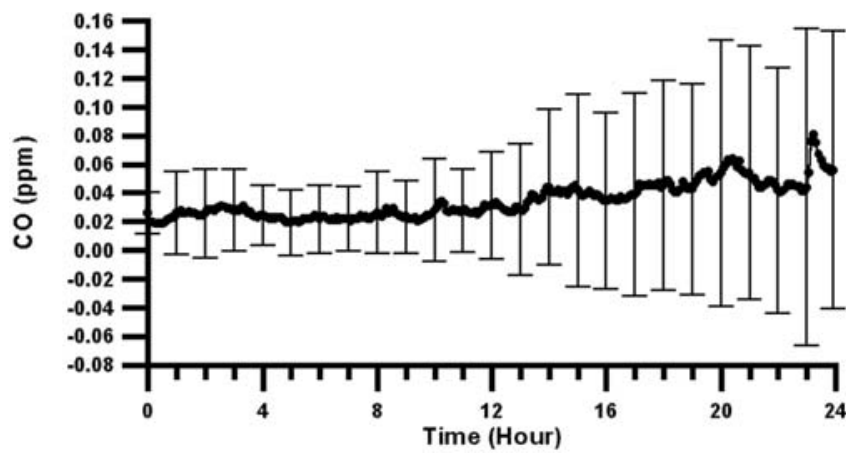

Figure 7. Mean diurnal variation over Arabian Sea.

to the spatial coverage, the $\mathrm{CO}$ diurnal peaks did occur in the AN, but not at the same time of the day. As ascertained from the co-ordinates of the ship available from the housekeeping data, the cruise tracks were parallel to the latitudes: covering about 200 nautical miles in a day along the longitude. This too may add to the time zone difference riding on the temporal pattern of $\mathrm{CO}$ data measured.

As no characteristic diurnal pattern in $\mathrm{CO}$ was observed, the mean diurnal patterns for the cruise period over Bay of Bengal and Arabian Sea were arrived at separately and are shown in figures 6 and 7 along with hourly standard deviation as error bars. While arriving at the mean diurnal pattern, the change in local time due to shift in longitudes was taken into account and the $\mathrm{CO}$ data have been processed so that the values corresponding to the same time zone and the ocean atmosphere were considered to be uniform. Suitable changes were made to the time of observation corresponding to the changes in the longitude. It is clear from the figures that the mean diurnals over both Bay of Bengal and Arabian Sea were similar and both show an increasing trend in the late afternoon

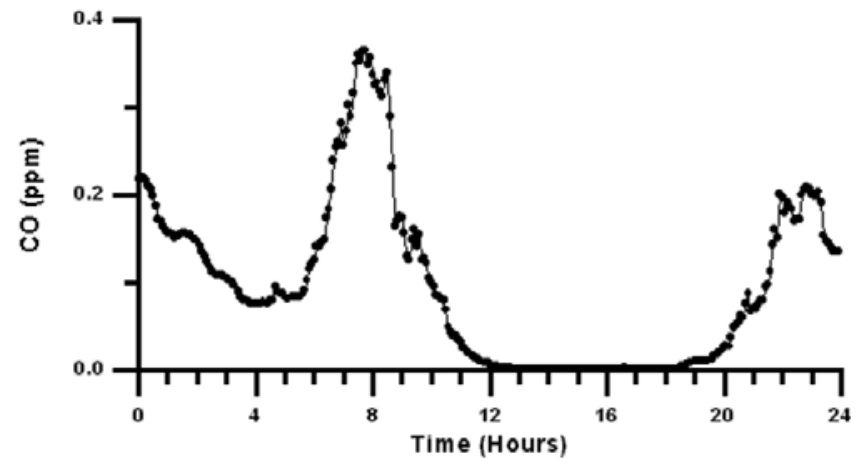

Figure 8. Diurnal variation of $\mathrm{CO}$ at Thiruvananthapuram (March 2004).

hours. This supports the observations from the diurnal patterns mentioned in the previous paragraph.

\subsection{CO over land}

CO was being measured continuously from 2003 at Thiruvananthapuram $\left(8.52^{\circ} \mathrm{N}, 76.91^{\circ} \mathrm{E}, 15 \mathrm{~m}\right.$ ASL), a tropical coastal site. A distinct feature observed in the $\mathrm{CO}$ diurnal pattern over land is that it has two peaks, one in the morning $(\sim 8 \mathrm{~h}$ IST $)$ and the other in the evening $(\sim 22: 30 \mathrm{~h}$ IST). This feature is like the diurnal patterns of atmospheric carbon (Babu and Moorthy 2002; Suresh Babu and Krishna Moorthy 2002). This suggests that similar atmospheric dynamics control both of them. The diurnal variation of $\mathrm{CO}$ over the tropical coastal station, Thiruvananthapuram depends on the change in boundary layer height, wind speed and direction, i.e., sea and land breeze activities (Mohankumar et al 2004). The morning peak is observed prior to the onset of sea breeze and the peak depends on the fumigation effect of the boundary layer. As the day advances, the boundary layer height and hence, the vertical circulation increases and the CO levels are diminished. In the late evening, the breeze reverses (directed from the urban area) and the shallow nocturnal layer forms. The associated inversion nearly inhibits vertical mixing of CO. Both these processes are conducive for increase in CO concentration. Similar mechanism controls the diurnal variation of atmospheric black carbon (Babu et al 2002) also. Being a clean coastal site, with lesser traffic and absence of industries, the average $\mathrm{CO}$ concentration at the measurement site in Thiruvananthapuram was about 100 ppb. Figure 8 shows the monthly mean diurnal variation of $\mathrm{CO}$ at Thiruvananthapuram in an earlier year (April 2004) for the same season as that of ICARB. Similar patterns were obtained at climatically and geographically different sites as revealed from the earlier measurements (Mohankumar et al 


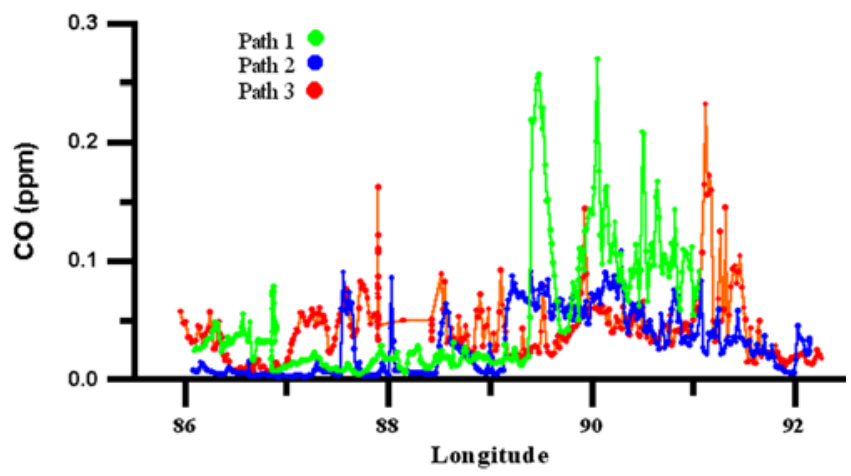

Figure 9. Variation of $\mathrm{CO}$ with longitude over Bay of Bengal.

2004, 2006), but the magnitudes of the CO concentrations were different.

\subsection{Effect of proximity of land on $C O$}

$\mathrm{CO}$ over oceans is generally lower compared to that over land (Gross et al 2005). Deeper penetration of solar UV radiation to lower troposphere in the tropics and the abundance of water vapour have a higher probability of production of the short lived $\mathrm{OH}$ radical. $\mathrm{OH}$ is a preferential natural sink of CO compared to methane (Yurganov 2000). Apart from the emission from the seas, which is very low compared to the sources in the land; another important source of $\mathrm{CO}$ in the marine air is the transport from land. This is evident from figure 9, which shows the variation of $\mathrm{CO}$ with longitude. As shown in figure 2, most part of the cruise path was parallel tracks along the east-west direction, parallel to the equator, with an approximate $2^{\circ}$ latitude width. As expected, $\mathrm{CO}$ concentrations were low in locations far from the coast in the ocean compared to those near the coast. Figure 9 shows a plot of variation of $\mathrm{CO}$ with longitude along three different paths from $86^{\circ} \mathrm{E}$ to $92^{\circ} \mathrm{E}$ longitudes, keeping the latitude constant at $15^{\circ}, 17^{\circ}, 19^{\circ}$ of $\mathrm{N}$ respectively. It is evident from the plot that $\mathrm{CO}$ shows an enhancement towards the higher longitude region; i.e., the Bangladesh coastal region. The beginning of the first path $\left(19^{\circ} \mathrm{N}, 86^{\circ} \mathrm{E}\right)$ is closer to the Indian coast and accordingly there is a buildup in $\mathrm{CO}$ levels. It is therefore clear that the proximity of land affects the $\mathrm{CO}$ concentration directly. CO near the coast went up to $0.25 \mathrm{ppm}$ and is in agreement with earlier measurements (Gros et al 2005; Keiichi Ohta 1997; Khalil and Rasmussen 1994). Similar effects are discernible in figures 4 and 5 on Day no. 4 (at 4-6 h in figure 4) and on Day 17 (at 8-12 h in figure 5) due to proximity to land. On the first occasion, the ship was near the Bengal coast where coal mines and associated industries exist in the

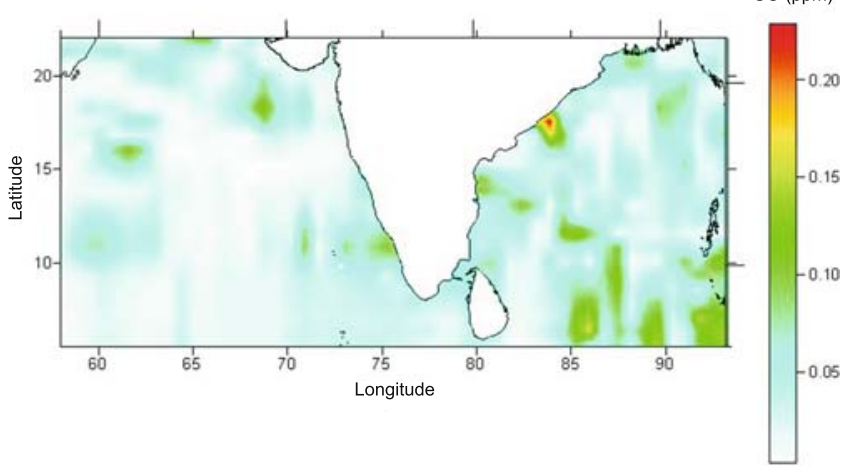

Figure 10. Spatial variation of CO.

main land. On the second occasion the ship was near the possibly polluted Mumbai coast.

From figure 10, which represents the spatial variation of CO over Bay of Bengal and Arabian Sea plotted with respect to latitude and longitude, it is evident that $\mathrm{CO}$ over Bay of Bengal was more than that over the Arabian Sea. This also supports the fact that proximity of land directly affects CO. Bay of Bengal is in between two landmasses and is more vulnerable to the continental wind-driven outflow of pollutants into the oceans. The cruise tracks proximal to the states of West Bengal, Orissa and Jharkhand in India have higher industrial effluents. With respect to the cruise tracks, Arabian Sea has much wider coverage (more than $10^{\circ}$ longitude) than Bay of Bengal. Also, geographic convergence of land is more in the Bay than that in the Arabian Sea. This is a possible reason for the higher rate of fluctuations in the $\mathrm{CO}$ values in the Bay of Bengal than that in the Arabian Sea. CO over Arabian Sea was steadier, as it is many times more Open Ocean than the Bay of Bengal.

\subsection{Effect of wind driven transport}

While analysing the continuous data, sharp rises in the $\mathrm{CO}$ values of very short duration $(\sim 20$ to 30 minutes) were observed. To examine those sharp rises in $\mathrm{CO}$, the available wind speed and direction data (at $1 \mathrm{~h}$ intervals) and the ship speed (at 1 minute intervals) and direction data were processed to derive the true wind speed and direction using vector analysis. The Automatic Weather Station (AWS) data from the ship deck were carefully examined to identify the wind direction within $30^{\circ}$ cone of the air inlet. The ship exhausts can cause only sharp transients in the CO pattern and they cannot be sustained, as the air inlet to the instruments is carefully located so as to have minimum interference in the measurements. Those peaks in $\mathrm{CO}$ occurring at true wind speed and direction interfering with the inlet to the analyser 


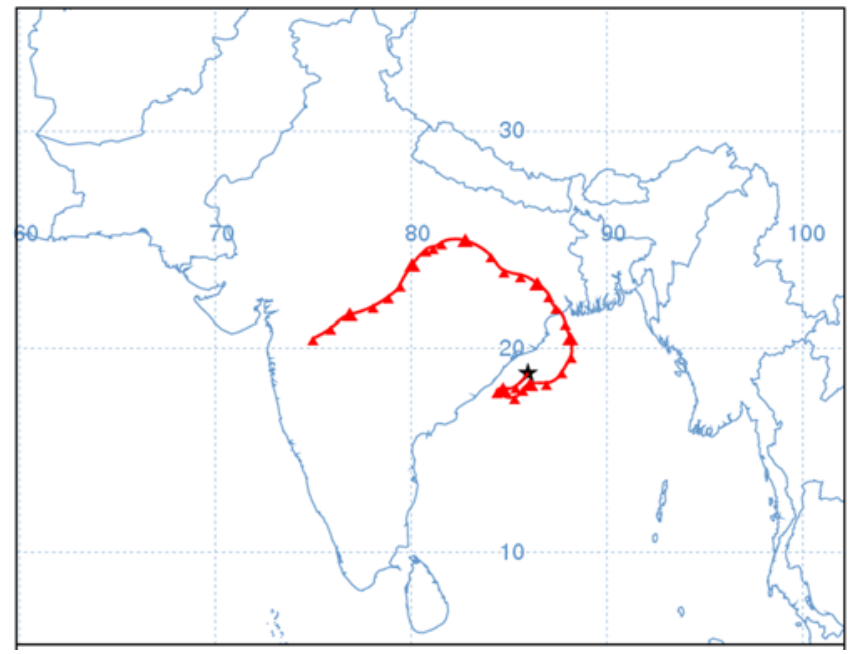

Figure 11. Backward trajectory during high CO episode in Bay of Bengal.

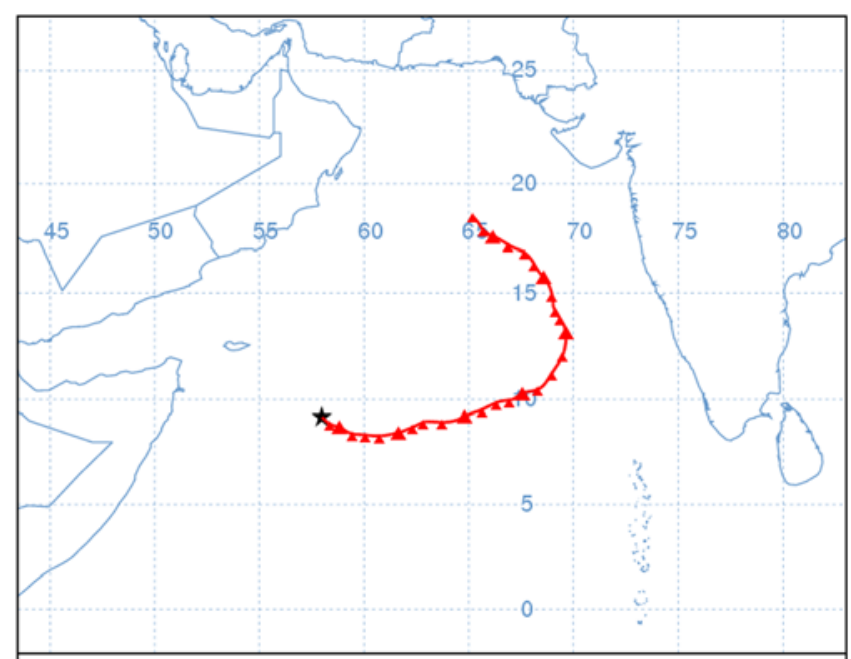

Figure 12. Backward trajectory during low $\mathrm{CO}$ episode in Arabian Sea.

were not included for analysis in the continuous data.

To study the effects of wind driven longrange transport in altering the concentration of $\mathrm{CO}$ in the maritime air, backward trajectories of seven days duration were computed using the NOAA HYSPLIT model available online at www.arl.noaa.gov/ready/hysplit4.html. Backward trajectories give only a highly averaged picture, as the minimum data interval available is six hours. Wind trajectories were calculated at a height of $15 \mathrm{~m}$ above mean sea level because the measurement site in the vessel was about $15 \mathrm{~m}$ from the sea level. Back trajectory analyses show that during high $\mathrm{CO}$ episodes, airmass flow was from the continent to the Bay of Bengal, suggesting that transport from land by wind is a crucial factor in affecting the ambient $\mathrm{CO}$ levels (figure 11); whereas in the Arabian Sea, most of the time the wind trajectories were confined to the maritime zones only (figure 12). This could be the reason for lower and steadier CO levels over the Arabian Sea.

\section{Conclusions}

The principal outcome of the analysis of the $\mathrm{CO}$ data collected during the ICARB ocean segment over the Bay of Bengal and Arabian Sea are:

- Diurnal CO pattern both over the Bay of Bengal and Arabian Sea show single peak in the afternoon hours whereas in the land it was a double peak pattern. The recurrence of the peaks does not show a temporal consistency as the ship had spatial coverage.

- The peaks did have a magnitude of 100125 ppbv, a high amplitude variation compared to the peaks observed in the diurnal pattern in the remote island location in the Indian Ocean, by earlier measurements.

- Long-range transport and proximity to the land did account for the CO highs observed aboard. $\mathrm{CO}$ was high near the coast than in locations far from the coast.

- CO concentration over the Bay of Bengal was higher than that over the Arabian Sea.

\section{Acknowledgements}

The authors thank Dr. C B S Dutt, ISRO-GBP Office, ISRO Headquarters and Prof. R Sridharan, Director, SPL, VSSC, Thiruvananthapuram for providing an opportunity to participate in the campaign. We are grateful to Dr. M Sudhakar and the National Centre for Antarctic Ocean Research, DOD, Government of India for the ship and onboard facilities. We are also grateful to the officers and staff of ORV Sagar Kanya for all support. We thank the entire ICARB team, especially Dr. K Krishna Moorthy and the SPL team for all the support and co-operation. We thank the NOAA website (www.arl.noaa.gov/ready/hysplit4.html) for computing the backward trajectories. Also, the authors thank the Director, CESS for all support.

\section{References}

Babu S S and Moorthy K K 2002 Anthropogenic impact on aerosol black carbon mass concentration at a tropical coastal station: A case study; Curr. Sci. 81 1208-1214. 
Climate Change 2001 IPCC Report 2001: The scientific basis: Contribution of Working Group 1 to the Third Assessment Report of the Intergovernmental Panel on Climate Change, Cambridge University Press, New York.

Erickson D J III and Taylor J A 1992 3-D tropospheric CO modelling: the possible influence of the ocean; Geophys. Res. Lett. 19 1955-1958.

Gros V, Bonsang B, Sarda-Esteve R and Royer A 2005 Diurnal variation of carbon monoxide in the remote marine atmosphere; Geophys. Res. Abstracts 707546.

Jockel P, Brenninkmeijer C A M and Crutzen P J 2002 A discussion on the determination of atmospheric $\mathrm{OH}$ and its trends; Atmos. Chem. Phys. Disc. 2 1261-1286.

Keiichi Ohta 1997 Diurnal Variation of Carbon Monoxide Concentration in the Equatorial Pacific Region; J. Oceanogr. 53 173-178.

Khalil M A K and Rasmussen R A 1994 Global decrease in atmospheric Carbon Monoxide Concentration; Nature 370 639-641.

Khalil M A K 1995 Decline in Atmospheric Carbon Monoxide Raises Questions About its Cause; Earth in Space 8(3) 7 .
Mohankumar G, Sampath S and Jeena V S 2004 Continuous measurement of ambient carbon monoxide at a tropical coastal station; J. Ind. Goephys. Union 8(3) 205-210.

Mohankumar G, Sampath S and Jeena V S 2006 Features of atmospheric carbon monoxide at two different coastal environments; J. Ind. Geophys. Union 10(4) 279-284.

Moorthy K K, Satheesh S K and Babu S S 2006 ICARB: An Integrated Campaign for Aerosols, gases and Radiation Budget; Proc. of SPIE 6408 6408P, 0277-786X/06/\$15, doi: $10.1117 / 12$. 696110 .

Springer-Young M, Erickson D J III and Carsey T P 1996 Carbon Monoxide Gradients in the Marine Boundary Layer of the North Atlantic; J. Geophys. Res. 1014479.

Suresh Babu S and Krishna Moorthy K 2002 Aerosol black carbon over a tropical coastal station in India; Geophys. Res. Lett. 29(23) 2098, doi:10.1029/2002.

Swinnerton J W, Linnenbom V J and LaMontagne R A 1970 The ocean: a natural source of carbon monoxide; Science $167984-986$.

Yurganov L 2000 Carbon monoxide inter-annual variations and trends in the Northern Hemisphere: Role of $\mathrm{OH}$; IGACtivities Newsletter, September 15-18. 